NBER WORKING PAPER SERIES

CROSS-COUNTRY CONVERSION FACTORS FOR

SECTORAL PRODUCTIVITY COMPARISONS

Johannes Van Biesebroeck

Working Paper 10279

http://www.nber.org/papers/w10279

NATIONAL BUREAU OF ECONOMIC RESEARCH
1050 Massachusetts Avenue
Cambridge, MA 02138
January 2004

I would like to thank Francette Koechlin for providing me with the OECD price data. The views expressed herein are those of the authors and not necessarily those of the National Bureau of Economic Research.

(C)2004 by Johannes Van Biesebroeck. All rights reserved. Short sections of text, not to exceed two paragraphs, may be quoted without explicit permission provided that full credit, including (C notice, is given to the source. 
Cross-country Conversion Factors for Sectoral Productivity Comparisons

Johannes Van Biesebroeck

NBER Working Paper No. 10279

January 2004

JEL No. D24, F14, F31, O47

\begin{abstract}
International comparisons of the level of labor or total factor productivity have used exchange rates or purchasing power parity (PPP) to make output and capital comparable across countries. Recent evidence suggests that aggregate PPP holds rather well in the long run, making it a good basis for comparison. At the same time, sectoral deviations from PPP are very persistent, raising the need for disaggregate price measures to make disaggregate productivity comparisons. Sectoral differences in the importance of nontradables make it even more important to work with sectoral prices when country-comparisons are made at the sectoral level. Mapping prices from household expenditure surveys into the industrial classification of sectors and adjusting for taxes and international trade, I obtain a sector-specific PPP measure. The few previous studies that used sectoral prices only had conversion factors available for a single year. With price data for 1985, 1990, 1993, and 1996, I am the first to test whether the constructed conversion factors adequately capture differential changes in relative prices between countries. For some industries--Agriculture, Mining, and less sophisticated manufacturing sectors--the indices prove adequate. For most other industries, aggregate PPP is a superior currency conversion factor.
\end{abstract}

Johannes Van Biesebroeck

Department of Economics

University of Toronto

150 St. George Street

Toronto, ON M5S 3G7

CANADA

and NBER

jovb@chass.utoronto.ca 
Aggregate productivity comparisons are performed all the time. A country's GDP per capita is cited in news report or newspapers without even providing a definition. A lot of people, not limited to economists, are aware that the rise to prominence of the United States's economy has been accompanied by an accession in the world ranking of GDP per capita from. While the United Kingdom was approximately one third more prosperous per capita in 1870, the United States had a lead of approximately one third in 1960. Similarly, the rapid economic development in a country like South Korea raised its GDP per capita from only $7 \%$ of the U.S. level in 1960 to $44 \%$ in 2001. While the United States rules in GDP per capita, the high productivity of some European workers, like the Belgians and French, is still apparent from their top spots in the ranking of GDP per hour worked. The impressive growth performance of Mexico in the last two decades is even more impressive when placed into the context of their low capital stock. Labor productivity in the business sectors stood at $32 \%$ of U.S. labor productivity in 1995 , while they attained $79 \%$ of the U.S. total factor productivity level in the same year. ${ }^{1}$

To calculate the previous statistics, domestic output in local currency for each country was converted to a common denominator, usually the U.S. dollar, using purchasing power parities (PPP). These are constructed for each country from price surveys, conducted approximately every three years. Prices of a common basket of goods are aggregated using expenditure weights, producing a conversion factor that is less volatile than the exchange rate. The prices of identical goods are collected in each country. Goods are picked to represent the output of the entire economy, not only tradable and financial assets. This large statistical enterprise is a coordinated effort of the statistical departments of the United Nations, Eurostat, the OECD, the IMF and the World Bank. Economists are most familiar with the PPPs from the Penn

\footnotetext{
${ }^{1}$ Statistics cited are taken from Maddison (1995), the U.N. web site, and various OECD reports.
} 
World Tables data, collected by Summers, Heston, and Kravis, that has been disseminated widely.

While the use of PPP as convergence factor to put nominal amounts in the same currency is now so ubiquitous to be fairly uncontroversial, their use is limited to aggregate output comparisons. A separate PPP is calculated for investment goods, to make TFP comparisons between countries. Prices of investment goods can-and do - evolve differently from the evolution of the general price level. To compare TFP levels of two countries at different points in time, changes in the relative price of capital have to be taken into account. To compare sectoral productivity between countries, one should exert similar caution. Fore example, if the (relative) prices of textiles and machinery evolve differently in the United States and Japan, it will obviously not be correct to use the same aggregate PPP to convert both Japanese textile and machinery output into U.S. dollar. If a constant PPP masks increasing textile prices in Japan relative to the U.S. and decreasing machinery prices, Japanese productivity growth in textiles is overestimated and vice versa in machinery. Without a sectoral equivalent to the PPP, one inevitably gets the productivity comparison wrong.

One of the most important applications for sectoral productivity comparisons is in the convergence debate. It is now fairly well established that convergence in labor productivity, or more broadly in GDP per capita, did not take place for the world at large. Nevertheless, there was some convergence within the more narrowly defined category of industrialized or

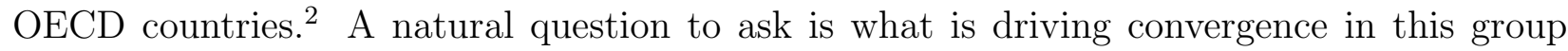
of countries. Are all sectors converging to the same extent? Is it the decline in importance (share in GDP) of sectors with inherently large productivity differentials, like agriculture?

\footnotetext{
${ }^{2} \mathrm{~A}$ engaging nontechnical account of the convergence debate is in Easterly (2001). A more technical overview of the debate with recent evidence and arguments can be found in a symposium in the July 1996 issue of the Economic Journal or in Durlauf and Quah (1999).
} 
Or, alternatively, are service sectors that account for an ever larger portion of GDP more comparable across countries? It is also possible that the increased trade intensity between developed economies, especially in manufacturing, drives the convergence results. In order to answer any of the above question, one needs to calculate sectoral productivity differences, at several points in time.

While aggregate comparisons are widespread, the same is not true for sectoral comparisons. First, I illustrate that sectoral prices do change and that it affects productivity comparisons. I provide a solution - sectoral PPPs - and assess their validity. Finally, I show that sectoral convergence is happening for the limited set of countries studied here. The remainder of the paper is organized in eight sections that elaborate on each of the following nine points:

1. International comparisons of output or productivity require currency converters to express output in comparable units, much like productivity comparisons over time require deflators to convert nominal values into real ones.

2. For sectoral comparisons, a proper currency conversion factor should reflects relative sectoral prices at the moment of conversion and capture the relative evolution of sectoral prices in both countries if it were calculated at different points in time.

3. Comparing the actual change in sectoral deflation rates between a number of countries and the U.S., reveals that relative prices do evolve differently in most countries.

4. Sector-specific conversion factors can be constructed from unit value ratios, as in van Ark and Pilat (1993), or from consumer prices, as in Jorgenson, Kuroda, and Nishimizu (1987) or as is done for aggregate PPP.

5. I construct sectoral PPPs for 14 countries in four different years. Even though conver- 
gence factors are only needed in a single year to study sectoral convergence, one needs to observe them at different points in time to test their validity.

6. Sørensen (2001) showed that the convergence results for manufacturing obtained using aggregate PPP in Bernard and Jones (1996) are not base year invariant. For some sectors, e.g. total manufacturing or chemical products, sectoral PPP does not suffer from the same problem; for other sectors, e.g. financial services, the problem largely remains.

7. A direct test for the validity of the sectoral PPPs compares sectoral price deflation relative to the U.S. with changes in PPP. Results remain mixed: sectoral PPP performs well in agriculture, mining and some manufacturing sectors, but in sophisticated manufacturing and service sectors aggregate PPP is better.

8. Four reasons why sectoral PPP might fail to capture relative price changes are explored.

9. Finally, I show evidence of $\beta$ - and to a lesser extent of $\sigma$-convergence in labor productivity for most sectors from 1980 to 1999, using the most appropriate PPP in each sector.

\section{International comparisons}

To compare output or productivity between countries one needs to convert local currency values into a common unit of measurement. Exchange rates are often deemed inappropriate because they fluctuate a lot and are only affected by tradable and financial assets. The proper conversion factor into U.S. dollar, for example, should measure the price in each country using that country's currency for a basket of goods that is representative of the output that is compared, rescaled such that it would cost $\$ 1$ in the U.S. For GDP, this is exactly what the PPP is designed to accomplish. For example, the relative labor productivity level of the 
Japanese economy relative to the U.S. in 1970 is calculated as:

$$
\left(\frac{L P^{J}}{L P^{U S}}\right)_{70}=\frac{L P_{70}^{J, \Psi} / P P P_{70}^{¥ / \$}}{L P_{70}^{U S, \$}}
$$

with $P P P^{¥ / \$}=\frac{P^{\sharp}}{P^{\Phi}}$, the number of yen needed to purchase the same basket of goods in Japan that costs $\$ 1$ in the U.S. $L P$ is simply total output divided by total employment or any other input measure that is deemed appropriate.

To compare the evolution of relative productivity levels over time, say from 1970 to 2000, two approaches are possible. If we had a lot of faith in the currency conversions, we can compare the productivity level using current prices in both years and track its evolution. The following calculation measures the change in relative productivity level between Japan and the U.S. from 1970 to 2000 :

$$
\frac{\text { relative } \mathrm{LP}_{00}^{J / U S}}{\text { relative } L P_{70}^{J / U S}} \equiv \frac{\left(\frac{L P^{J}}{L P^{U S}}\right)_{00}}{\left(\frac{L P^{J}}{L P^{U S}}\right)_{70}}=\frac{\frac{L P_{00}^{J, \Psi} / P P P_{00}^{¥ / \$}}{L P_{00}^{U S, \$}}}{\frac{L P_{70}^{J, ¥} / P P P_{70}^{¥ / \$}}{L P_{70}^{U S, \$}}}
$$

If we do not observe the currency convergence factors in both periods or if we have more faith in price deflators, we can calculate real output or productivity growth separately for each country and compare the growth rates.

$$
\frac{1+L P G_{70 / 00}^{J}}{1+L P G_{70 / 00}^{U S}} \equiv \frac{\left(\frac{L P_{00,70}}{L P_{70}}\right)^{J(¥)}}{\left(\frac{L P_{00,70}}{L P_{70}}\right)^{U S(\$)}}=\frac{\frac{L P_{00}^{J, ¥} /\left(\frac{P_{00}}{P_{70}}\right)^{¥}}{L P_{70}^{J, ¥}}}{\frac{L P_{00}^{U S, \$} /\left(\frac{P_{00}}{P_{70}}\right)^{\$}}{L P_{70}^{U S, \$}}}
$$

The nominal values for 2000 have to be converted into real (1970) values, which is indicated by $L P_{00,70}$. In equation (2), the yen denominated Japanese production is converted into dollars 
at each point in time to track how the relative productivity of Japan evolves. In equation (3), the change in productivity for Japan and the U.S., in real 1970 prices, is compared directly to judge the evolution of their relative performance.

Obviously, for (2) and (3) to produce the same result, the price deflators and currency converters have to be related. Rearranging both equations reveals that they have to satisfy

$$
\frac{P P P_{00}^{¥ / \$}}{P P P_{70}^{¥ / \$}}=\frac{\left(\frac{P_{00}}{P_{70}}\right)^{¥}}{\left(\frac{P_{00}}{P_{70}}\right)^{\$}} .
$$

The ratio of the currency conversions factors at both points in time has to equal the ratio of price deflation in both countries. If one country experiences more rapid inflation than the other, its currency should depreciate in PPP terms. In theory, $P P P^{¥ / \$}$ is defined as $\frac{P^{¥}}{P^{\Phi}}$ and (4) should hold. In practice, both sides of the equation are calculated from different data and equality is not guaranteed.

While the country with the highest productivity growth rate should have a higher relative productivity level in 2000 than in 1970, it does not speak to the level comparison. If the high growth country was already the productivity leader in 1970, it has unambiguously increased its lead. If it was lagging in 1970, the gap might have become smaller or the relative ranking might have reversed. To distinguish each of the three possible scenarios, both comparisons(1) and (2) or (3) - have to be carried out.

This implies that to assess convergence, the currency convergence has to be performed at least once, but not necessarily more than once. For example, Bernard and Jones (1996) calculate relative productivity levels for one base year (1985) and trace the relative productivity paths for different countries without further currency conversions, using (3). Sørensen (2001) 
confirms that for GDP per worker in the entire business sector exactly the same results would be obtained if the currency conversion would be performed in a different year.

One of the important predictions of the Solow growth model (Solow 1956) is that growth rates between countries will only differ in the short run. Assuming technology spills across borders without impediments, countries will all convergence to the same steady state per capita growth rate. This prediction has been tested and rejected frequently at the aggregate level. An obvious explanation is that technology differences are persistent and different countries will converge to different steady states. An open question is whether convergence fails to the same extent in all sectors. Intuitively, one might expect technology to spread more easily in sectors where output is traded intensely. Such sectoral comparison are complicated by the necessity of currency convergence factors that are appropriate for each sector, which I turn to next.

\section{Sectoral international comparisons}

At disaggregate levels, few comparisons of productivity levels between two countries have been carried out, partly because it is difficult to find proper currency exchange factors. In general, if prices change differently across sectors, it will not be correct to use the same conversion factor for different sectors. Continuing with the previous example, the productivity difference between Japan and the U.S. in 2000 can be written as the product of the difference in 1970 and the relative growth in the intervening period.

$$
\left(\frac{L P^{J}}{L P^{U S}}\right)_{00}=\left(\frac{L P^{J}}{L P^{U S}}\right)_{70} \frac{\left(\frac{L P_{00,70}}{L P_{70}}\right)^{J}}{\left(\frac{L P_{00,70}}{L P_{70}}\right)^{U S}}
$$




$$
\begin{aligned}
& \frac{L P_{00}^{J, \Psi} / P P P_{00}^{¥ / \$}}{L P_{00}^{U S, \$}}=\frac{L P_{70}^{J, \Psi} / P P P_{70}^{¥ / \$}}{L P_{70}^{U S, \$}} \frac{\left(\frac{L P_{00}^{J, \Psi} /\left(\frac{P_{00}}{P_{70}}\right)^{¥}}{L P_{70}^{J \Psi}}\right)}{\left(\frac{L P_{00}^{U S, \$} /\left(\frac{P_{00}}{P_{70}}\right)^{\$}}{L P_{70}}\right)} \\
& =\frac{L P_{00}^{J, ¥} \times\left(P P P_{70}^{¥ / \$} \frac{\left(\frac{P_{00}}{P_{70}}\right)^{¥}}{\left(\frac{P_{00}}{P_{70}}\right)^{\$}}\right)^{-1}}{L P_{00}^{U S, \$}}
\end{aligned}
$$

If convergence is taking place, the two terms on the right hand side of (5) should be negatively correlated.

The same relationship between the conversion factors and deflation rates has to hold as before for both sides of the equation to equal one another. In logarithms, it amounts to

$$
\log \frac{P P P_{00}^{¥ / \$}}{P P P_{70}^{\# / \$}}=\log \left(\frac{P_{00}}{P_{70}}\right)^{¥}-\log \left(\frac{P_{00}}{P_{70}}\right)^{\$}=\dot{p}^{¥}-\dot{p}^{\$}
$$

The change in the convergence factor has to match the relative inflation rates between the two countries. For two sectors with different relative price changes the same aggregate PPP, or even the exchange rate, will not be able to satisfy equation (6).

As an example of the potential pitfalls from using aggregate PPP, consider photographic cameras in Japan. In 1985, cameras were relatively expensive in Japan, costing 268 yen per dollar worth of camera in the U.S., while the aggregate PPP was 218. By 1996, prices dropped relative to the U.S. and a camera costing $\$ 100$ in the U.S. could be bought for only 8600 yen in Japan. Even if convergence in productivity was perfect, it would not be picked up using aggregate PPP. Assume, for example, that in 1985 Japan was less productive, but that the entire difference was eliminated through faster productivity growth, such that by 1996 both countries were equally productive in camera production. The relative productivity growth, the second term in the decomposition in (5), is not affected by PPP. All that is needed are 
deflators that capture the relative price drop of cameras in Japan relative to the U.S. If the aggregate PPP of 218 is used to convert the high nominal amount in yen in $1985, L P_{85}^{J ¥}$, into 1985 dollars, rather than the true price of 268, we I overestimate Japanese initial productivity. On the left hand side of (5), the low nominal amount in yen in $1996, L P_{96}^{J, ¥}$, produces an underestimate of the Japanese productivity level if the aggregate PPP of 166 is used to convert it into 1996 dollars, rather than the true price of 86. The puzzling conclusion would be that a country with relatively high productivity level in camera production in 1985 enjoyed higher productivity growth than the U.S., but has fallen behind in relative productivity by 1996. A sector with the reverse price trend, such as local transportation, would yield opposite, equally puzzling results. The sector would appear to improve its productivity level relative to the U.S., even though it enjoyed lower productivity growth if correct price deflators are used to compare 1996 and 1985 statistics.

The principle is more general than might appear from the previous discussion. To comparing productivity for some industry in country $A$ at time 1 with country $B$ at time 0 , we need both a price adjustment, to bring units at time 1 back to time 0 , and a factor to convert country $A$ 's currency to country $B$ 's:

$$
\frac{L P_{1}^{A}}{L P_{0}^{B}}=\frac{L P_{1}^{A} /\left(\frac{P_{1}}{P_{0}}\right)^{A} / P P P_{0}^{A / B}}{L P_{0}^{B}} .
$$

Alternatively, we can first put country $A$ 's productivity level in country $B$ 's currency at time 1 and perform the price deflation using country $B$ prices:

$$
\frac{L P_{1}^{A}}{L P_{0}^{B}}=\frac{L P_{1}^{A} / P P P_{1}^{A / B} /\left(\frac{P_{1}}{P_{0}}\right)^{B}}{L P_{0}^{B}}
$$


which will give the same result, as long as

$$
\frac{P P P_{1}^{A / B}}{P P P_{0}^{A / B}}=\frac{\left(\frac{P_{1}}{P_{0}}\right)^{A}}{\left(\frac{P_{1}}{P_{0}}\right)^{B}}
$$

which boils down to equation (4) or (6) again. The ratio of price deflation rates between countries should equal the ratio of currency conversion factors at different points in time. ${ }^{3}$

In sum, to compare labor productivity between two countries at one point in time, we need to observe a currency conversion factor. To see how this relative productivity evolves over time, we need, in addition, conversion factors in all years or price deflators in each country. If price deflators are used to track relative productivity over time, it is important that the currency converter properly captures relative price differences between the countries. Otherwise, convergence results will depend on the year of currency conversion.

\section{Is there a problem?}

Bernard and Jones (1996) use aggregate PPPs to investigate convergence among 14 OECD countries separately for six broadly defined sectors. Sørensen (2001) proposes three tests to verify whether their convergence results are invariant to the choice of base year for the

\footnotetext{
${ }^{3}$ In principle, we can even go one step further and compare different industries, $i$ and $\iota$, in different countries at different times. In addition to converting country $A$ 's currency to country $B$ 's and bringing units at time 1 back to time 0 , we can adjust the labor productivity statistics of each industry by the relative capital intensity and compare total factor productivity:

$$
\frac{T F P_{i 1}^{A}}{T F P_{\iota 0}^{B}}=\frac{L P_{i 1}^{A} /\left(\frac{P_{i 1}}{P_{i 0}}\right)^{A} / P P P_{i 0}^{A / B} /\left(\frac{K_{i 0}^{A} / P P P_{K 0}^{A / B} / L_{i 0}^{A}}{K_{\iota 0}^{B} / L_{\iota 0}^{B}}\right)^{\frac{1}{2}\left(s_{i}^{A}+s_{\iota}^{B}\right)_{0}^{K}}}{L P_{\iota 0}^{B}}
$$

The capital-labor ratio adjustment is weighted by the average capital share of each sector that is compared and country A's capital is converted using a capital goods PPP.
} 
currency conversion. If equation (4) holds with equality in each sector the base year would not matter, but he finds that the aggregate PPPs do not pass the test, especially not for manufacturing. The price of manufactured goods relative to the aggregate price level must have evolved differently in different countries.

A more direct check whether there is any cause for concern compares the deflation rates, used in real output statistics, across countries and sectors. In two possible situations is the use of aggregate PPP adequate. If relative prices are stable in all countries, the evolution of the aggregate price level is all that is relevant and aggregate PPP will be adequate. This is obviously a matter of degree. The question is how long a time period can one assume that relative prices do not change. If price inflation in Japan equals U.S. price inflation in every sector, there is also no problem. Even though the aggregate PPP cannot reflect the relative price change for each sector, it will not introduce a bias because all countries are affected similarly. If the currency convergence is only performed once with aggregate PPP, each convergence test assumes that relative prices between countries, e.g. the price of machinery in terms of textiles in Japan relative to the U.S., are unchanged from that base year. In each of the two previous situations, this assumption holds.

Unfortunately, over a ten year period, neither of the two situations even remotely reflects the relative price evolution of manufactured products in a set of 14 OECD countries. In Figure 1, I plot for ten manufacturing sectors the relative rate of inflation from 1985 to 1996 for three countries relative to the price inflation in the U.S. ${ }^{4}$ The relative rates are normalized

\footnotetext{
${ }^{4}$ The manufacturing sectors are ISIC Revision 3 sectors 15-16: Food products, beverages and tobacco; 1719: textiles, textile products, leather and footwear; 20: Wood and products of wood and cork; 21-22: Pulp, paper, paper products, printing and publishing; 23-25: Chemical, rubber, plastics and fuel products; 26: Other non-metallic mineral products; 27-28: Basic metals and fabricated metal products; 29-33: machinery and equipment; 34-35: Transport equipment; 36-37: Manufacturing not elsewhere classified (NEC) and recycling.
} 
by the average relative inflation rate for manufacturing as a whole. If all sectors in a country experience the same relative inflation evolution, each country should display a horizontal line at one.

This is obviously not the case for Canada, Japan, and the Netherlands. Two of these three countries, Canada and Japan, are large trading partners of the U.S. and had the most similar inflation experience. On the graph, industries are ranked from low to high U.S. inflation. Sectors that experienced lower than average inflation in the U.S., e.g. machinery and equipment and metal products, experienced relatively higher inflation in the other three countries. Sectors with higher inflation in the U.S., such as food, wood, and paper, generally experienced less inflation in the other countries. Seven Japanese industries experienced higher inflation than their U.S. counterparts, while this was the case for only two Canadian and four Dutch industries.

\section{[Figure 1]}

As a result, it would not be correct to use the same aggregate PPP to convert Dutch machinery or food output into dollars. Figure 1 indicates that between 1985 and 1996 prices of machinery relative to the average manufacturing good rose $57 \%$ faster in the Netherlands than in the U.S. This decomposes as follows. The average Dutch price level rose by $11 \%$, while machinery became only $9 \%$ more expensive. In the U.S., the average manufacturing price level increased more, by $21 \%$, while machinery became $34 \%$ cheaper, quality adjusted. In relative terms, the inflation rate for machinery in the Netherlands was $43 \%$ higher than in the U.S., while the average manufacturing price increase was $10 \%$ lower. Combined, this results in a $57 \%$ increase of the relative price of machinery in terms of average manufacturing goods in the Netherlands relative to the U.S. $\left(1.10^{*} 1.43=1.57\right)$. The reverse is true for food 
prices which dropped $32 \%$ in relative price in the Netherlands, relative to the U.S.' relative price evolution.

To make the example even more concrete, I look for direct evidence of such price evolutions in the price surveys. In 1985, a standardized amount of flour costing $\$ 1$ in the U.S., would have set a Dutch consumer back 2.39 Dutch guilder. This could have been considered a steal as the Dutch guilder was trading at 3.3 per $\$$ and the aggregate PPP was 2.48 . By 1996, an amount of flour costing $\$ 1$ in the U.S. was priced at only 1.46 guilder in the Netherlands even though the aggregate PPP only dropped to 2.06. The relative price of flour relative to other goods has thus dropped in the Netherlands, relative to its evolution in the U.S. It went from $4 \%$ cheaper than the cost of the average bundle of goods in the U.S. (2.39 versus 2.48), to $29 \%$ cheaper (1.46 versus 2.06). A similar pattern holds for a whole range of food products.

Evidence for the relative increase in Dutch machinery prices is less easy to detect. There are some products that experience an increase in price relative to the U.S. such as heaters and air conditioners, vacuum cleaners, and record players. A lot more products such as products of boilermaking, machinery for working wood, refrigerators, and television sets, have become cheaper, but the price decline was less than the decrease in aggregate PPP, contributing to the relative price increase for machinery. Still, examples of products that saw prices decline faster than the aggregate PPP abound, which works in the opposite direction of the general trend. One possibility is that manufactured goods experienced more rapid price declines than service goods, even more so in the Netherlands than in the U.S. An alternative possibility is that the output price deflators in the U.S. go further in making adjustment for quality improvements than in other countries. The price surveys look for standardized products and do not have such a problem. In that case, the price increase for Dutch machinery in Figure 
1 combines price decreases with quality improvements, for which the Dutch statistical office makes less adjustment than their American counterparts.

The differential price evolutions in different sectors is not confined to three countries. Figure 2 plots the relative price changes in three industries relative to the average manufacturing price change for all 14 countries. Relative price changes for each country are again normalized by the relative price change in the U.S. for the respective industry. Inflation in the machinery and equipment industry was the lowest of all U.S. industries. Not surprising then, that all other countries saw relatively higher price increases in that industry, but the differences between countries are very large. In Korea, machinery prices relative to average manufacturing declined as much as in the U.S., while in Belgium relative machinery prices went though the roof. The reverse is true for the paper, pulp, printing, and publishing industry, which experienced the highest inflation of all U.S. industries, but saw relative price decreases in other countries relative to the U.S. The basic metals and fabricated metal products industry is intermediate. In some countries, like Norway and Portugal, these goods became cheaper relative to the U.S., while in the United Kingdom or Korea they became more expensive.

[Figure 2]

Figure 2 confirms that relative prices evolve differently across countries and sectoral convergence factors are necessary. For some countries, like Belgium, Portugal, or Mexico, the price evolution differs enormously from that in the U.S. across industries. The bias, if the same aggregate PPP is used for all industries, will be huge. For other countries, like Japan or Canada, the relative prices changed somewhat, but the error made by ignoring price trends will be more limited.

The evidence presented in this section demonstrates that relative prices of different indus- 
tries do evolve differently across countries. Accurate productivity comparisons will have to use currency conversion factors that adequately reflect relative prices. If the same conversion factor is used for each industry, the relative productivity level at each point in time will be sensitive to the base year in which the currency conversion is carried out. A sampling of food product prices provided some idea that price surveys conducted to construct aggregate PPPs may contain the data needed to construct sectoral PPPs. A cursory look at machinery prices, reveals that the validity of such conversion factors should be tested and not be taken for granted.

\section{Other sectoral currency conversions}

Even though few researchers have actually constructed sector-specific conversion factors, I am obviously not the first to compare sectoral output across countries. Researchers have constructed sectoral PPPs from unit values ratios, using producers' prices, or from consumer prices, obtained from retail price surveys. The first approach was pioneered by van Ark and Pilat (1993) and is explained in detail, with recent advances, in van Ark and Timmer (2001). Its appeal stems from the natural concordance between price and output measures and the possibility to control accurately for changes in product mix. A drawback is the need for "double deflation", to control for changes in intermediary goods prices.

The second approach is also used to construct aggregate PPP and first applied to sectoral comparisons in Jorgenson, Kuroda, and Nishimizu (1987). Price and expenditure information comes from consumer surveys and direct retail price surveys. It has been the more popular approach, even though the output concept is usually taken from the production side of the national accounts, while prices correspond to the expenditure side. In a comment on van Ark 
and Pilat (1993), Jorgenson mentions:

The unit value ratios are preferable, in principle, because they represent ratios of producers' prices for the two countries being compared. [...] The practical disadvantages of unit value ratios largely outweigh their conceptual advantages, so the purchasing power parities of Kravis and his associates [...] are far more satisfactory. ("Comment" on van Ark and Pilat (1993), p. 53)

Jorgenson, Kuroda, and Nishimizu (1987) use the approach outlined in Jorgenson and Kuroda (1990) to compare sectoral productivity between Japan and the U.S. Using the same methodology, Conrad and Jorgenson (1985) extend the results and include Germany in the comparison. Lee and Tang (2001) perform similar comparisons between Canada and the U.S. for Industry Canada. As far as I am aware, this is an exhaustive list of the studies that construct sectoral prices. ${ }^{5}$

Jorgenson and Kuroda (1990) present the methodology to compare prices internationally, starting from 153 commodity groups compiled by Kravis, Heston, and Summers (1978) for 1970. In the bilateral productivity comparisons between the U.S. and other countries, the consumer prices are adjusted for trade, indirect taxes and transportation margins, to better approximate producer prices. These adjustments require inter-industry accounts and pose great requirements on the data. I will be able to perform some, but not all of the adjustments. Pilat (1996) applies the methodology to a larger set of countries, starting from more detailed price surveys compiled by Eurostat and the OECD. Approximately 220 basic headings are available that aggregate prices on 2500 goods and services for $1990 .^{6}$ The detailed list of

\footnotetext{
${ }^{5}$ Using sectoral PPPs in a productivity comparison using gross output, as in Jorgenson and Kuroda (1990), or adjusting unit value ratios for "double deflation", as in van Ark and Timmer (2001), requires detailed and internationally harmonized input-output tables. This is beyond the scope of this paper and I will limit myself to comparing value added per worker, using sectoral PPPs to convert value added.

${ }^{6}$ Harrigan (1999) uses PPPs which are specific for a number of GDP components. These are published by the OECD and aggregated from the same basic headings. While they are available for the same years as I work with, they do not correspond well to the industries that provide the output measures.
} 
goods for which price are available are mapped into industrial sectors. Aggregation of the individual good prices produces a sectoral PPP. A more detailed description of all calculations and judgement calls involved is presented in the next section.

The sectoral PPPs are used to compare productivity between countries at different points in time. For example, to compare sector $i$ at time $t$ between Japan and the U.S. we need

$$
P P P_{i t} \equiv \frac{P_{i t}^{\Psi}}{P_{i t}^{\Phi}} .
$$

For the same comparison at a later time, $t+1$, we need in principal

$$
P P P_{i t+1} \equiv \frac{P_{i t+1}^{\Psi}}{P_{i t+1}^{\Phi}}
$$

while in practice one can rely on

$$
P P P_{i t+1}=P P P_{i t} \times \frac{\left(\frac{P_{i t+1}}{P_{i t}}\right)^{¥}}{\left(\frac{P_{i t+1}}{P_{i t}}\right)^{\$}} .
$$

All previously mentioned studies avoid making the price comparisons directly, as in (8), at multiple dates. Instead, they construct sectoral PPPs for a single year and extrapolate the comparison forward or backward in time, relying on (9). This is correct as long as the deflation rates in both countries are equally successful in distinguishing genuine price increases from output or quality increases. It remains to be seen whether this holds equally well for all sectors.

Bernard and Jones (1996) and Dollar and Wolff (1988) ignore the possible differential evolution in relative prices between different countries and use aggregate PPP to convert sectoral 
output. Sørensen (2001) showed that equation (9) is violated for the manufacturing sector if aggregate PPP is combined with sectoral price deflators. Obviously, aggregate PPP does not necessarily capture the different evolution of relative prices for manufacturing products in different countries. For the total business sector, equation (9) did hold with aggregate PPP and the relevant deflation rates. Because PPPs and deflation rates are constructed from different prices, equation (9) is not even guaranteed to hold if the levels of aggregation match (approximately). The total business sector results instill some confidence in the expenditure PPP approach.

The implicit assumption that differential evolutions of relative prices between countries are unimportant or that they are equally well captured with contemporaneous cross-country comparisons as with relative price changes measured within each country separately, is mirrored in another comment on van Ark and Pilat (1993) by Frank Lichtenberg:

Another, less serious limitation of the paper's approach is that the authors constructed "benchmark" estimates of relative productivity levels for only a single year-1987; ("Comment" on van Ark and Pilat (1993), p. 58).

All studies using sector-specific conversion rates to compare productivity levels between countries over time have committed the same sin and similarly assumed that (9) holds. As far as I know, I am the first to actually test the adequacy of sectoral PPPs.

\section{$5 \quad$ My sectoral currency conversions}

To control for relative price differences between countries, we need sector-specific currency

convergence factors, e.g. $P P P^{¥ / \$} \equiv\left(\frac{P^{¥}}{P^{\$}}\right)$. I follow the expenditure approach, as Jorgenson and coauthors did, and construct them from consumer prices. Sectoral PPPs are calculated 
for 18 OECD countries in four years: 1985, 1990, 1993, and 1996. Even though a convergence factor is only needed in a single year to study sectoral convergence, we need to observe it at different points in time to test whether it adequately captures relative price changes. A number of validity checks are performed in the following two sections.

The construction of sectoral PPPs has three components to it. First, goods from consumer expenditures and price surveys are mapped into the industrial classification of sectors. Second, prices are aggregated to the level of output and input. Third, adjustments are made for trade, indirect taxes, and differences in retail or wholesale margins. ${ }^{7}$

The starting point are surveys conducted in almost all OECD countries that collect prices and expenditures on approximately 3000 standardized products. A basket of comparable goods and services are chosen to be representative of the entire economy. Products consumed by consumers, businesses and government are surveyed and aggregated to 207 basic heading categories. These are the most detailed product categories for which expenditure weights can be estimated and which are available for all countries. Background information on the survey and on the construction of aggregate PPP from only the price and expenditure data can be found in OECD (1999).

Similarly as Jorgenson and Kuroda (1990) and Pilat (1996), I map the "basic heading" expenditures categories into the industrial classification of sectors. I use the two digit ISIC Revision 3 as this is the level of detail for which comparable output and input statistics are available across countries. This corresponds roughly to the detail of three digit SIC industries. Obviously a number of judgement calls have to be made to perform the mapping. I experimented with different criteria yielding largely similar results. ${ }^{8}$

\footnotetext{
${ }^{7}$ Lack of data forces me to drop the last adjustment.

${ }^{8} \mathrm{~A}$ complete list of the mapping is available upon request. Three basic headings were omitted as they
} 
To calculate a single price index at the most detailed industry classification, some basic heading categories have to be aggregated. By necessity, this was done using expenditure shares. Further aggregation - to a more aggregated industry breakdown - uses total sales, where available, or value added shares. For example, the two basic headings "cigarettes" and "other tobacco products" are both mapped into ISIC industry 16 "manufacture of tobacco products". The PPP for this industry is obtained by weighing the prices for both headings by expenditure shares. Further aggregation, to construct a PPP for the combined industries 15-16 "food products, beverages, and tobacco" uses output shares as weight.

Because not all consumption is produced locally, one should adjust for the trade content of consumption. Similarly, some of the domestic production is sold to other countries, presumably at world prices. The adjustment is premised on the assumption that exports and imports are exchanged with the rest of the world using the exchange rate. The pound sterling value of British cigarette production is converted into dollars at the going exchange rate, when exported to the U.S. Equivalently, if Great Britain imports from the U.S. an amount of cigarettes that sells for $\$ 1$ in the U.S., I assume that it costs one over the dollar per pound exchange rate. For each country, the expenditure PPP that is observed in the price surveys is the average of the PPP domestic producers receive ( $P P P$ expend), which is weighted by the production over consumption, and the exchange rate $(E R)$, which is weighted by net imports

could not be matched to any specific industry: 1182022 "Other personal goods and effect", 1431011 "other products" (the very last, catch-all category), 1500000 "change in stocks". Two other basic headings were omitted as they capture purchases abroad: 1191011 and 1600000 . One potentially problematic assumption is to include consumption of fixed capital by hospitals, nonprofit institutions, and educational institutions, in the sector where they sell their services. Presumably, the cost of these expenditures will be passed on to consumers in the price of their services. As I don't know the breakdown between buildings, different types of equipment, furniture, etc., the only other option is to omit those expenditures. 
over consumption. The following identity holds in U.S. dollar prices

$$
P P P_{\text {expend }} \times \text { Consumption }=P P P_{\text {prod }} \times \text { Production }+E R \times \text { Imports }-E R \times \text { Exports }
$$

while in domestic pound prices the following identity holds as well,

$$
\text { Consumption }=\text { Production }+ \text { Imports }- \text { Exports. }
$$

Combining both identities produces the following adjustment for the $P P P$ expend $^{\mathrm{s}}$ :

$$
P P P_{\text {prod }}=P P P_{\text {expend }}+\left(E R-P P P_{\text {expend }}\right) \times \frac{\text { Exports }- \text { Imports }}{\text { Production }} .
$$

If the product is more expensive domestically than in the U.S. and the country is a net importer, the relevant PPP to convert domestic production into U.S. dollar will be even higher than the observed expenditure PPP. If the country is a net exporter of goods for which the expenditure PPP exceeds the U.S. exchange rate, the production PPP is adjusted downwards, because exporters will have to settle for lower prices.

Finally, prices are adjusted for indirect taxes, because observed PPPs include taxes while I want to compare output net of taxes. The adjustment for country $i$ follows Pilat (1996),

$$
P P P_{\text {net }}^{i}=P P P_{\text {gross }}^{i} /\left(\frac{1+\left(\frac{\text { Tax }- \text { Subsidy }}{\text { Production }}\right)_{i}}{1+\left(\frac{\text { Tax-Subsidy }}{\text { Production }}\right)_{U S A}}\right) .
$$

The gross prices are divided by the relative net tax difference with the U.S., the comparison country for all other countries. The observed indirect tax ratios vary by country, industry, 
and year. They are taken from the ISDB data set, produced by the OECD. ${ }^{9}$ When sectoral tax data was missing, the average tax rate over all non-missing years is used. If data was missing in all years, the tax ratio of the industry one-up in the aggregation is used. For countries with all tax data missing, no adjustment could be made.

In some industries, the sectoral PPP measures that I obtain differ quite a lot from the aggregate PPP. As an example, Table 1 lists the exchange rate, aggregate PPP, and sectoral PPPs in several industries. The calculated PPP for the "Total Business" sector differs from the published aggregate PPP because of aggregation differences (production instead of expenditures), the trade and indirect tax adjustment, and the exclusion of government services and nonprofit activities from "Total Business". In some countries, e.g. Greece and Portugal, many government services are heavily subsidized producing a much lower aggregate PPP than "Total Business" PPP. In theory, the sectoral PPPs should be superior to the aggregate PPP. In practice, the imperfect aggregation and adjustments for trade and taxes might introduce biases.

[Table 1]

Because I have price survey data for several years, I am able to test the validity of the sectoral PPPs. In particular, I can verify whether they satisfy the relationship between PPP and output deflators as described by equations (4), (6), or (9). Appropriate conversion factors will produce measures of $\beta$ - or $\sigma$-convergence that are independent of the year in which the currency convergence is carried out. I illustrate this for manufacturing and a number of other sectors in Section 6. A more direct test is whether changes in the appropriate conversion factors match changes in relative prices, which I check in Section 7.

\footnotetext{
${ }^{9}$ The ISDB data set is discontinued after 1998.
} 


\section{Base year invariant convergence results}

Commenting on an earlier paper by Bernard and Jones (1996), Sørensen (2001) showed that aggregate PPP was inappropriate to study convergence in the manufacturing sector. The initial productivity level (in 1970) for each country relative to the U.S. depended on the year in which the currency conversion was carried out when aggregate PPP was used to convert manufacturing output in U.S. dollar. This variation has important consequences for the convergence results. For the service sector, which accounts for more than $50 \%$ of GDP in most developed economies, the use of aggregate PPP did not pose the same problem. With the sectoral PPPs, I replicate the tests for manufacturing and show that the results are now robust to the year in which the currency conversion is carried out. As a result, the $\beta$ - and $\sigma-$ convergence conclusions do not depend on the base year anymore.

In the top row of Figure 3, I reproduce the three different graphs from Sørensen (2001) for my data set using aggregate PPP. ${ }^{10}$ The bottom row shows the corresponding graphs when sectoral PPP is used for currency conversions. While there are noticeable trends in the top graphs, these virtually disappear in the bottom graphs. The sectoral PPPs seem to capture relative price differences and their changes over time reasonably well.

Each line in the top-left graph represents the initial relative productivity (in 1985) of one country. The years on the X-axes indicate the year in which the currencies are converted to U.S. dollar, while real growth rates are used to bring nominal amounts back to 1985. For each country, the statistics are normalized by the average over the different possible base years. If the currency conversion did not depend on the base year the lines would be horizontal at

\footnotetext{
${ }^{10}$ The analysis is carried out for a larger number of countries, 18 versus 14 in previous work. I limit the sample to the period 1985-1996, because I can only calculate sectoral PPP for this period.
} 
zero for each country. This is clearly not the case for aggregate PPP. The graph below plots the corresponding relative productivity numbers when the currency conversion is carried out using sectoral PPP. Only four estimates can be obtained, one for each year I have sectoral conversion factors. Relative productivity is fluctuating marginally less in the bottom figure. ${ }^{11}$

The middle graphs plot the coefficient estimate and $95 \%$ confidence bound for $\beta$-convergence, again using the different base years to convert output into U.S. dollar. The relevant coefficient is obtained from an OLS regression of average real productivity growth over the sample period on log initial productivity pooling all countries. If the currency conversion were base year invariant, we would find a horizontal line. A line above zero would be evidence of divergence, below zero of convergence. The results using aggregate PPP hint at divergence if an early base year was used and at convergence for later base years. None of the pointestimates are significantly different from zero, which led Bernard and Jones (1996)—who used 1985 as base year - to conclude no convergence was taking place in manufacturing. Using the appropriate sectoral PPP for manufacturing, in the middle-bottom graph, suggests neither convergence nor divergence, independent of the base year.

Finally, the graphs on the right provide an estimate of $\sigma$-convergence. The standard deviation of productivity levels across countries is plotted for each year normalized by the standard deviation in 1985. Each base year for the currency convergence generates a different curve. In the top graph, only four of the twelve possible curves are included, those for the years with sectoral PPP available. The line using aggregate PPP in 1996 is relatively flat. The standard deviation of labor productivity hardly changes over the years, suggesting that countries are neither converging or diverging. Using aggregate PPP from any of the

\footnotetext{
${ }^{11}$ While this is hard to gauge from the figures, it does show up in the standard deviation by country, calculated similarly as in Sørensen (2001). Results are not reported as they are based on only 4 years for sectoral PPP.
} 
earlier years, on the other hand, produces evidence of slight divergence, because the standard deviation increases over time. If the conversion factors were time invariant, all four lines would lie on top of each other. This is largely the case in the bottom graph using sectoral PPPs. Dispersion across countries has hardly changed over the years.

[Figure 3]

For illustrative purposes, I include the same convergence tests for two other industries, "chemical products" and "financial services and real estate" in Figure 4. Products in the former industry are well defined, relatively homogeneous across countries, and traded rather intensely. The convergence tests show a clear improvement when sectoral PPP is used instead of aggregate PPP. The latter industry produces more differentiated products, which are harder to compare across countries and much less traded internationally. The results with sectoral PPP turn out to be at least as sensitive to the choice of base year as results for aggregate PPP.

[Figure 4]

While it is difficult to decide whether sectoral PPPs are properly capturing relative price differences based on these graphs, the two examples in Figure 4 illustrate that they are unlikely to be equally successful for each industry. In the following section, I derive a more explicit test to what extent changes in sectoral PPPs mirror changes in relative deflation rates. I also investigate what sectors for which the conversion factors are appropriate have in common. 


\section{Direct comparison of relative price evolutions}

An alternative way to verify the accuracy of the sectoral PPPs, is by looking at price changes directly. If relative sectoral PPPs correspond to relative prices in the economy, changes in sectoral PPP should correspond to sectoral deflation rates relative to the corresponding U.S. deflation rate. If they do, they will automatically produce productivity comparisons that are invariant to the base year for the currency conversion.

Changes in sectoral PPP are readily obtained from the PPPs calculated in Section 5. Sector-specific relative deflation is constructed by differencing the nominal and real output growth rates from the STAN database. Both price changes are calculated from entirely different data sources, but they are supposed to measure the same relative price evolution. To make the comparison more concrete, recall that Japanese PPP for sector $i$ at time $t$ is calculated as

$$
P P P_{i t}^{¥ / \$}=\frac{P_{i t}^{¥}}{P_{i t}^{\Phi}} .
$$

The change over time is given by

$$
\begin{aligned}
\log \frac{P P P_{i t}^{\sharp / \$}}{P P P_{i t-1}^{¥ / \$}} & =\log \frac{P_{i t}^{\Psi} / P_{i t}^{\$}}{P_{i t-1}^{\Psi} / P_{i t-1}^{\$}} \\
& =\log \left(\frac{P_{i t}}{P_{i t-1}}\right)^{¥}-\log \left(\frac{P_{i t}}{P_{i t-1}}\right)^{\$} .
\end{aligned}
$$

The same price change can be calculated from a comparison of real and nominal output 
because

$$
\text { real } \mathrm{VA}_{i t}^{J, ¥}=\frac{\text { nominal } \mathrm{VA}_{i t}^{J, ¥}}{P_{i t}^{\Psi}}
$$

and

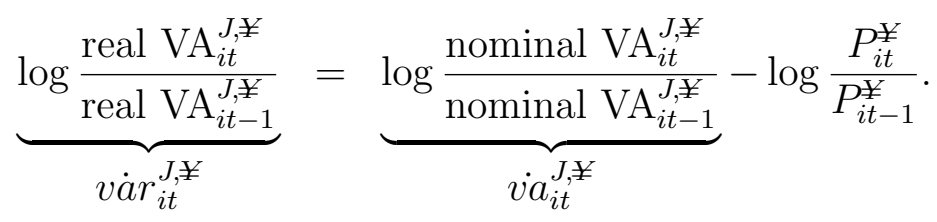

The deflation rate for industry $i$ in Japan is simply the difference in growth rates between nominal and real output. Subtracting the deflation rate for the U.S. - the benchmark countryproduces the same statistic as in (12):

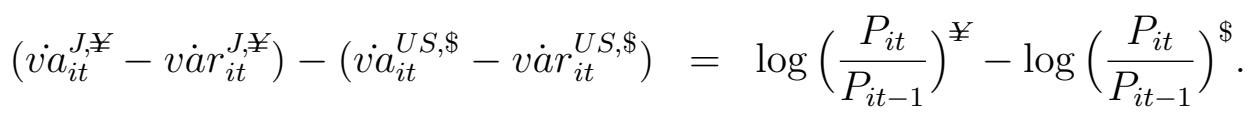

A first check is whether the two ways to calculate changes in relative sectoral prices, (12) and (13), produce similar results. Table 2 contains the correlation across countries between the change in PPP and the relative sectoral deflation and the number of countries for which both changes have the same sign. Results for both sectoral and aggregate PPP are included. Most researchers comparing productivity across countries, even at the sectoral level, have done so using aggregate rather than sectoral PPP. A switch to sectoral PPP is only warranted if these disaggregate price indices approximate relative price changes across countries better than the aggregate measures do.

The evidence is mixed. The results over the entire period, 1985 to 1996 are in Table 2. Only for Agriculture is sectoral PPP clearly superior, while only for Construction and Total 
Services both measures prefer aggregate PPP over sectoral PPP. In Mining and Quarrying the correlation between sectoral deflation and changes in PPP is higher for the sectoral measure, while the aggregate PPP measure is more likely to have the same sign. The reverse is true for Manufacturing and Electricity, Gas, and Water; the correlation is higher for aggregate PPP, but sectoral PPP is more likely to predict the direction of change correctly.

Even more troublesome are the results for a shorter period, spanning two consecutive price surveys, 1993 and 1996, in Table 3. For Agriculture, on one hand, and Construction and Total Services, on the other hand, the superiority of respectively sectoral and aggregate PPP is not unambiguous anymore. Moreover, for Mining and Quarrying, sectoral PPP is now unambiguously preferred, while for Manufacturing the correlation results now prefer the sectoral measure.

Results at a finer sectoral decomposition, often limited to a smaller set of countries, clear up some of the ambiguity. For almost all detailed Agriculture and Mining industries both measures in both time periods prefer sectoral over aggregate PPP. For most detailed Service industries aggregate PPP seems more appropriate. Only in Transport and Communication is sectoral PPP superior between 1993 and 1996, but aggregate PPP has a such a high correlation, 0.86, with relative sectoral deflation over the longer period that it still seems preferable. ${ }^{12}$

The detailed manufacturing industries fall roughly in three groups. In Food (15), Wearing Apparel (18), and Petroleum Products (23), the correlation is always at least 0.10 higher for sectoral PPP than for aggregate PPP. In Wood and Cork (20) and Rubber and Plastics (25) sectoral PPP also has better indicators, correlations and sign predictions, but the correlation

\footnotetext{
${ }^{12}$ More detailed service industries are not listed as the aggregate PPP measure dominates, except for education.
} 
is not always 0.10 higher than for aggregate PPP. For these five sectors sectoral PPP seems to be the most appropriate currency convergence factor. In the second group of five industries, aggregate PPP is preferred, because correlations always exceed those with sectoral PPP substantially: Leather and Footwear (19), Pulp and Paper (21), Metals (27-28), Machinery (29-33), and Not Elsewhere Classified (36-37). For the remaining manufacturing industries, it depends on the criterion or the time period one looks at whether sectoral or aggregate PPP is preferred. Often the correlation and sign predictions give opposite results and the results are generally rather close.

[Table 2]

[Table 3]

The finding in Sørensen (2001) that aggregate PPP is valid for services but not for manufacturing is confirmed in this data set, although I also find that not all manufacturing subsectors are alike. As an example of the importance of using sectoral PPP when it is appropriate, compare the convergence statistics in the first and second row of the top graph in Figure 4 for Chemicals and Chemical products (ISIC 23-25). This industry has one of the largest increases in correlation when moving from aggregate PPP to sectoral PPP, increasing from 0.65 to 0.78 , and 13 of the 14 signs are predicted correctly.

Another check on the relevance of the sectoral PPP is whether within each country the two measures for relative price changes are correlated. The results in Table 2 and 3 looked at the correlation between price changes and changes in PPP across countries separately for each industry. If the correlation was higher for sectoral PPP, it was deemed more appropriate for that industry. If aggregate PPPs are used to compare sectoral productivity, it is implicitly 
assumed that each industry experiences the same deflation rate as the aggregate economy or that the relative price change for each industry follows the same pattern as in the U.S in each country. No changes in relative prices are allowed.

The results in Table 4 look at correlations between the same price changes, but across industries and separately by country. For aggregate PPP, the change in PPP does not vary and correlations are zero by definition. Within most countries the change in sectoral PPP is positively correlated with the difference in deflation rate with the U.S. If the same sectors as

in Table 2 are included, in the first column, the average correlation is 0.15 , positive but low. Only two countries, Australia and Norway, have a negative correlation. If service sectors are excluded, as aggregate PPP was clearly preferred there, in the second column, most correlations are larger. If all non-service sectors that I have data on are included, in the third column, correlation are even higher, with an average across countries of 0.26 , but it is much higher for many countries. The sectoral PPPs clearly pick up relative price changes in the economy which are ignored by aggregate PPP.

[Table 4]

\section{Why sectoral PPP is inadequate for some industries}

Before turning to convergence results, I discuss a number of reasons why the sectoral PPPs might not be adequate measures of relative prices or why the calculations in the previous section might be a misleading test of their adequacy. The four reasons I consider are international trade, imperfections in the mapping, the absence of relative price changes, and quality adjustments. 
Sectoral PPP is derived from expenditure surveys, while consumers not only buy domestically produced goods. If goods are differentiated, some recorded prices will not be representative of locally produced goods. The expenditure weights used to aggregate prices at the most detailed level are also distorted by international trade. An increase in import penetration will have an effect on sectoral PPP as it changes the weighting within industries away from the correct one, based solely on domestically produced goods. Similarly, part of the domestically produced output is exported abroad and will not enter the PPP calculations, even though this output is still included to calculate relative deflation rates. If goods that are exported differ in a systematic way from other goods - e.g. they are cheaper than abroad-differences or changes in export intensity will similarly distort the weighting in the construction of sectoral PPPs. While the calculations in Section 5 control for trade, the adjustment is imperfect. Note also that aggregate PPP suffers from the same defect.

Many industries with high trade intensity did have a low correlation between changes in sectoral PPP and relative deflation in Table 2. The first industry, Agriculture, is the least exposed to trade of all the ones on which I had data available in 1996 and sectoral PPP did perform very well there. Machinery and Equipment, on the other hand, has the greatest trade exposure and aggregate PPP was clearly superior. ${ }^{13}$ Results in Table 5 confirm the negative relationship between trade and the performance of sectoral PPP in a more systematic way. A regression with as dependent variable the ratio of the correlation between changes in sectoral PPP and relative sectoral deflation to the same correlation with aggregate PPP, $\frac{\operatorname{corr}\left(\Delta P P P_{i}^{c}, \dot{p}_{i}^{c}-\dot{p}_{i}^{U S}\right)}{\operatorname{corr}\left(\Delta \overline{P P P^{c}} \dot{p}_{i}^{c}-\dot{p}_{i}^{U S}\right)}$, and as explanatory variable the average trade intensity produces a negative

\footnotetext{
${ }^{13}$ Only the Electricity, Gas and Water Supply industry traded less, but these goods are often subject to large subsidies or taxes and it is unlikely that relative price measures from consumer and producer side would match up. The average export and import shares as a percentage of production are $7 \%$ and $10 \%$ for Agriculture and $30 \%$ and $48 \%$ for Machinery and Equipment.
} 
coefficient. With only 31 observations the coefficient is not significantly different from zero, but the sign is as predicted.

A second reason for the poor results with sectoral PPP in some industries might be errors in the mapping from expenditure categories to industrial sectors. While the sectoral PPP measures are fairly robust to the criteria used to make the match, the price data might not contain sufficiently detailed information to be representative for each industry. Many service industries had especially few products allocated to them.

The second column in Table 5 contains results for a similar regression as before, but with the number of products allocated to the industry and the within-industry standard deviation of their prices as explanatory variables. The positive coefficient on the number of products suggests that PPP measures improve if they are based on more data. Perhaps surprisingly, a large standard deviation of relative prices across products is also associated with better PPP measures. One interpretation is that observing prices over a wide range, combined with expenditure weights, allows for a more precise estimate of average prices. Industries with PPP estimated based on a single product have less accurate measures, as expected.

A third situation where the use of sectoral PPP might make matters worse is for industries with low relative price changes. In that case, aggregate PPP will do nicely because aggregate price changes are invariably low for the countries included. The test in the previous section might produce misleading results. If relative deflation rates are very low or hardly vary across countries, correlation are bound to be low. The construction of sectoral PPP inevitably introduces some randomness, while there is no real problem to start with.

If the correlation rates are regressed on the size or the standard deviation of the absolute difference between the sectoral and economy-wide deflation rates across countries, the coef- 
ficients are both positive, see the third column of Table 5. If sectoral prices change in line with the aggregate price level, i.e. relative prices do not change, sectoral PPP does not bring much benefit, as shown already in Section 2. Alternatively, if differences between sectoral and aggregate prices are relatively homogeneous across countries, there is again no need for sector-specific conversion factors.

It turns out that for most service industries the standard deviations are very low. Lower than for any of the manufacturing industries. While the average relative price change across countries is high for many service industries, it is very uniform across countries. It is no surprise then, that aggregate PPP suffices for productivity comparisons in service industries. For manufacturing sectors, the standard deviations are much larger, on average twice as large, and in percentage of the total price change almost four times as large. Unfortunately, the sectors with the highest cross-country differences in relative price changes are also the ones most exposed to trade and sectoral PPP might not bring much relief, as discussed earlier.

Including the measures for all three reasons together, in the fourth column of Table 5, confirms the previous findings. Sectoral PPP performs well if trade is low, if sectoral prices change a lot and differently across countries, and if a lot of products are used to estimate PPP.

Finally, differences in the methods used in different countries to adjust for changes in product quality is a fourth reason why changes in sectoral PPP are imperfectly correlated with sectoral deflation rates. The statistical agencies in each country decompose nominal output changes into price and quantity changes, counting improved quality as higher quantity. Some countries are more aggressive in counting nominal increases as quality gains and subtracting them from price changes. This will lead to differences in the way sectoral deflation rates 
should be interpreted for different countries. The sectoral PPPs we construct do not face the same problem, because prices of exactly the same goods are compared simultaneously in each country. The relative price at any point in time is well-defined and easy to measure, as long as the same products are sold in both countries.

Industries with the most scope for quality change are sophisticated manufacturing and service industries. Exactly those where sectoral PPP did worst in Table 2. The computer industry, in Machinery and Equipment, probably provides the best example. The average price per computer is relatively constant over time in each country, but this masks a substantial improvement in quality over time. The price per unit for any characteristic consumers value - calculation speed, storage capacity of the hard drive, quality of the video outputdeclines constantly. To account for these quality improvements, statistical agencies estimate a decrease in the real price and use this to deflate - in this case inflate-industry output. If the adjustment procedure varies by country, which is very likely, the sectoral deflation rates cannot be compared across country. The Bureau of Labor Statistics in the U.S., for example, recently switched from a matched model approach to an adjustment based on hedonic regressions, see Pakes (2003). The relative price changes obtained by comparing sectoral deflation rates between countries and the ones obtained from changes in sectoral PPP will not measure the same thing anymore. It will also make the productivity comparison sensitive to the base year of currency conversion.

\section{Sectoral convergence}

Finally, I revisit the sectoral convergence results in the sample of OECD countries. I only look at labor productivity, as Bernard and Jones (1996) indicate that the results for TFP are 
largely identical. For each industry I use the convergence factor, sectoral or aggregate PPP, that was found to be most appropriate in Section 6. For industries were the choice of PPP was ambiguous, I used the correlation from 1985 to 1996 as tie-breaker, generally favoring aggregate PPP.

Because not all countries have data on all industries, the number of observations varies by industry. Some industries from Table 2 were aggregated if employment data was missing in subsectors. Both manufacturing and non-manufacturing industries are included. The time period covered is the 19 year period from 1980 to 1999. The period studied is solely determined by availability of real output and employment data. ${ }^{14}$ If relative prices are constant or the PPP measure captures changes in relative prices correctly, a currency conversion factor is only needed in a single year. PPP in 1996 is used for each throughout. ${ }^{15}$

The fourth column in Table 6 contains the $\beta$-convergence results. This measures the extent to which average productivity growth across countries is explained by the initial productivity level of each country. The reported statistic is the regression coefficient on the initial productivity level when average productivity growth over the full sample period is the dependent variable. The least squares regression is run separately by industry with countries as observations. If convergence is taking place, the regression coefficient will be negative. In Figures 3 and $4, \beta$-convergence statistics with confidence bounds were plotted in the middle graphs

\footnotetext{
${ }^{14}$ The data used here are for a more recent time period than in Bernard and Jones (1996). Using sectoral data classified by ISIC Revision 3 instead of Revision 2 limits the number of years one can go back. Because Revision 3 is closer to variations of the SIC classification - which are used in the U.S., Canada, the U.K., and Australia - and also to the more recently used NACE classification in the E.U., it was preferred.

${ }^{15}$ Results using PPP in 1985 are available upon request. The $\beta$-convergence results are almost identical. The $\sigma$-convergence results are less supportive of convergence in some industries. This might be because outliers matter more for $\sigma$-convergence. If the PPPs do not capture relative price changes accurately and convergence is taking place, this is what one could expect to find. Using the 1985 conversion rates, the standard deviation in 1980 is higher, not because productivity levels were more dispersed, but because the use of incorrect relative prices introduced additional variation.
} 
for all different PPP base years. The results in Table 6 show that virtually all sectors have negative coefficient estimates and that several are significantly different from zero. Manufacturing as a whole as well as several manufacturing subsectors display convergence. The convergence estimates for services industries are almost all significantly different from zero.

The fifth column in Table 6 contains $\sigma$-convergence results. This measures the change over time in standard deviation of productivity levels across countries. The reported statistic is the ratio of the standard deviation at the end of the period (1999) over the standard deviation at the beginning of the period (1980). ${ }^{16}$ If convergence is taking place, the ratio should be smaller than one. Using the 1996 PPP, I find convergence for 16 of the 23 industries. The average ratio is 0.90 . There is no obvious pattern in the industries that display the strongest $\sigma$-convergence. It comprises industries that produce highly tradable products-Mining or Machinery - and at the same time industries that produce nontradables - Electricity-GasWater or Wholesale and Retail Trade. The convergence results are also not related to the use of sectoral or aggregate productivity.

\section{[Table 6]}

In conclusion, the evolution of relative prices does differ by country and one should account for it when studying sectoral convergence. The sectoral PPP indices do the job relatively well for several "industrial" sectors. Using appropriate convergence factors, I showed that most industries experienced some convergence over the last two decades. A varied bunch of industries, notably Mining and Quarrying, Machinery and Equipment, Electricity, Gas and Water, and Restaurants and Hotels, experienced very strong convergence.

\footnotetext{
${ }^{16}$ Dividing the average standard deviation for the last two or three years by the average for the first two or three years produced very similar results.
} 


\section{References}

Bernard, A. B. and C. I. Jones (1996, December). Comparing Apples to Oranges: Productivity Convergence and Measurement Across Industries and Countries. American Economic Review 86(5), 1216-38.

Conrad, K. and D. W. Jorgenson (1985). Sectoral Productivity Gaps between the United States, Japan and Germany, 1960-1979. In H. Giersch (Ed.), Probleme und Perspectiven der Weltwirschaftlichen Etwicklung, pp. 335-47. Berlin: Duncker and Humblot.

Dollar, D. and E. N. Wolff (1988, November). Convergence of Industry Labor Productivity among Advanced Economies, 1963-1982. Review of Economics and Statistics 70, 549558.

Durlauf, S. N. and D. T. Quah (1999). The New Empirics of Economic Growth. In J. B. Taylor and M. Woodford (Eds.), Handbook of Macroeconomics, Volume 1A, Chapter 4. New York: North-Holland.

Easterly, W. (2001). The Elusive Quest for Growth: Economists'Adventures and Misadventures in the Tropics. Cambridge: MIT Press.

Harrigan, J. (1999). Estimation of Cross-country Differences in Industry Production Functions. Journal of International Economics 47, 267-93.

Jorgenson, D. W. and M. Kuroda (1990). Productivity and International Competitiveness in Japan and the United States, 1960-1985. In C. R. Hulten (Ed.), Productivity Growth in Japan and the United States, Volume 53 of NBER Studies in Income and Wealth, Chapter 2, pp. 29-57. Chicago, IL: University of Chicago Press.

Jorgenson, D. W., M. Kuroda, and M. Nishimizu (1987, March). Japan-U.S. Industrylevel Productivity Comparisons, 1960-1979. Journal of the Japanese and International Economies 1(1), 1-30.

Kravis, I. B., A. W. Heston, and R. Summers (1978). World Product and Income: International Comparisons of Real Growth Product. Baltimore: Johns Hopkins University Press.

Lee, F. C. and J. Tang (2001). Productivity Levels and International Competitiveness Between Canada and the United States. In D. W. Jorgenson and F. C. Lee (Eds.), Industry-Level Productivity and International Competitiveness Between Canada and the United States, Chapter 5, pp. 155-180. Ottawa: Industry Canada Research Monograph.

Maddison, A. (1995). Monitoring the World Economy 1820-1992. Paris: OECD.

OECD (1999). PPPs and Real Expenditures (1996 Results ed.). Paris: OECD.

Pakes, A. (2003, December). A Reconsideration of Hedonic Price Indexes with an Application to PC's. American Economic Review 93(5), 1578-97.

Pilat, D. (1996). Labour Productivity Levels in OECD Countries: Estimates for Manufacturing and Selected Service Sectors. Economics Department Working Papers 169, OECD, Paris.

Solow, R. M. (1956). A Contribution to the Theory of Economic Growth. Quarterly Journal of Economics 70, 65-94. 
Sørensen, A. (2001, September). Comparing Apples to Oranges: Productivity Convergence and Measurement Across Industries and Countries: Comment. American Economic Review 91 (4), 1160-67.

van Ark, B. and D. Pilat (1993). Productivity Levels in Germany, Japan, and the United States: Differences and Causes. Brookings Papers on Economic Activity: Microeconomics 2, 1-69.

van Ark, B. and M. Timmer (2001). PPPs and International Productivity Comparisons: Bottlenecks and New Directions. Working Paper for Joint World Bank-OECD Seminar on Purchasing Power Parities. 
Figure 1: Relative deflation rates for three countries across industries (1985-1996)

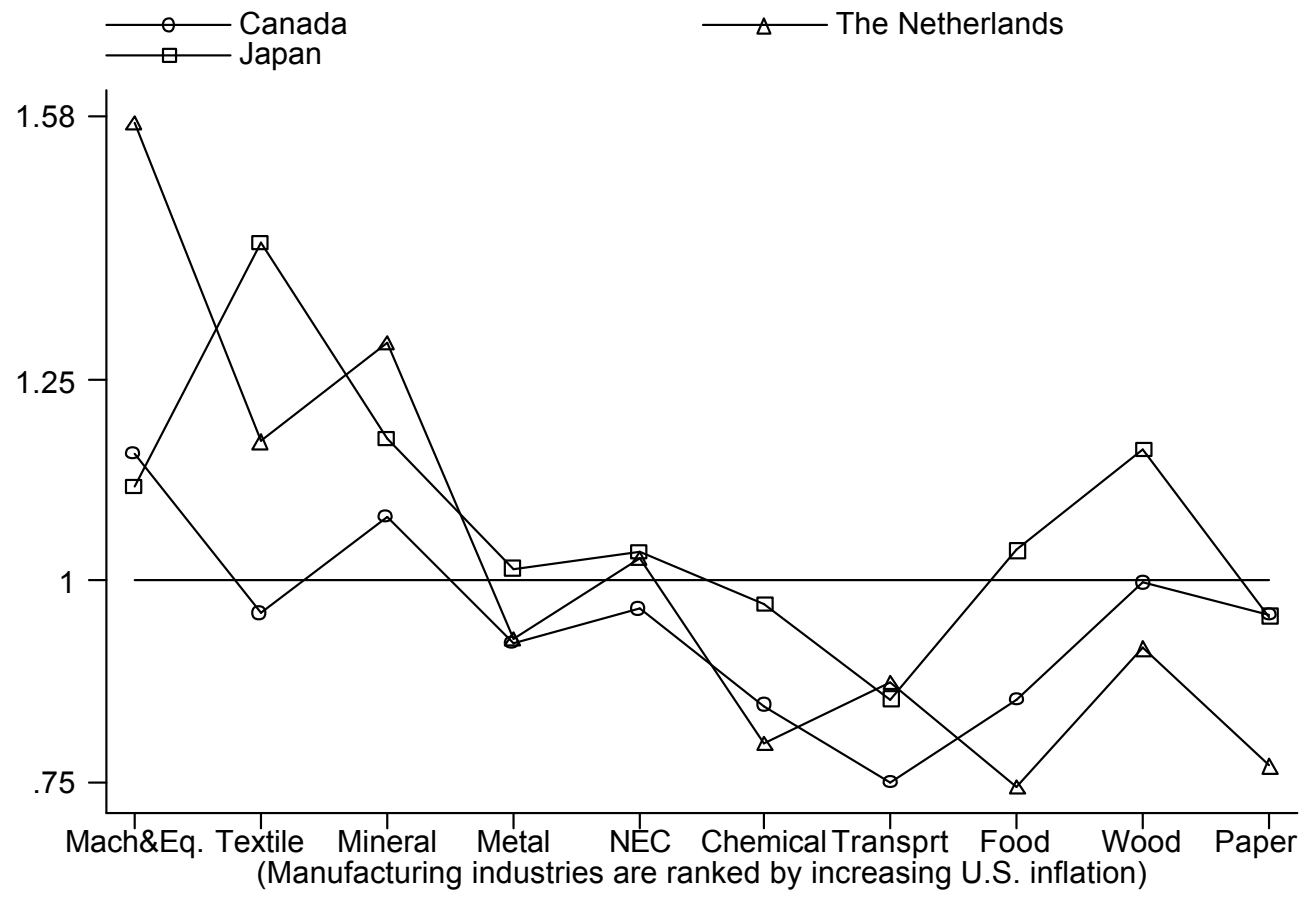

Figure 2: Relative deflation rates for three industries across countries (1985-1996)

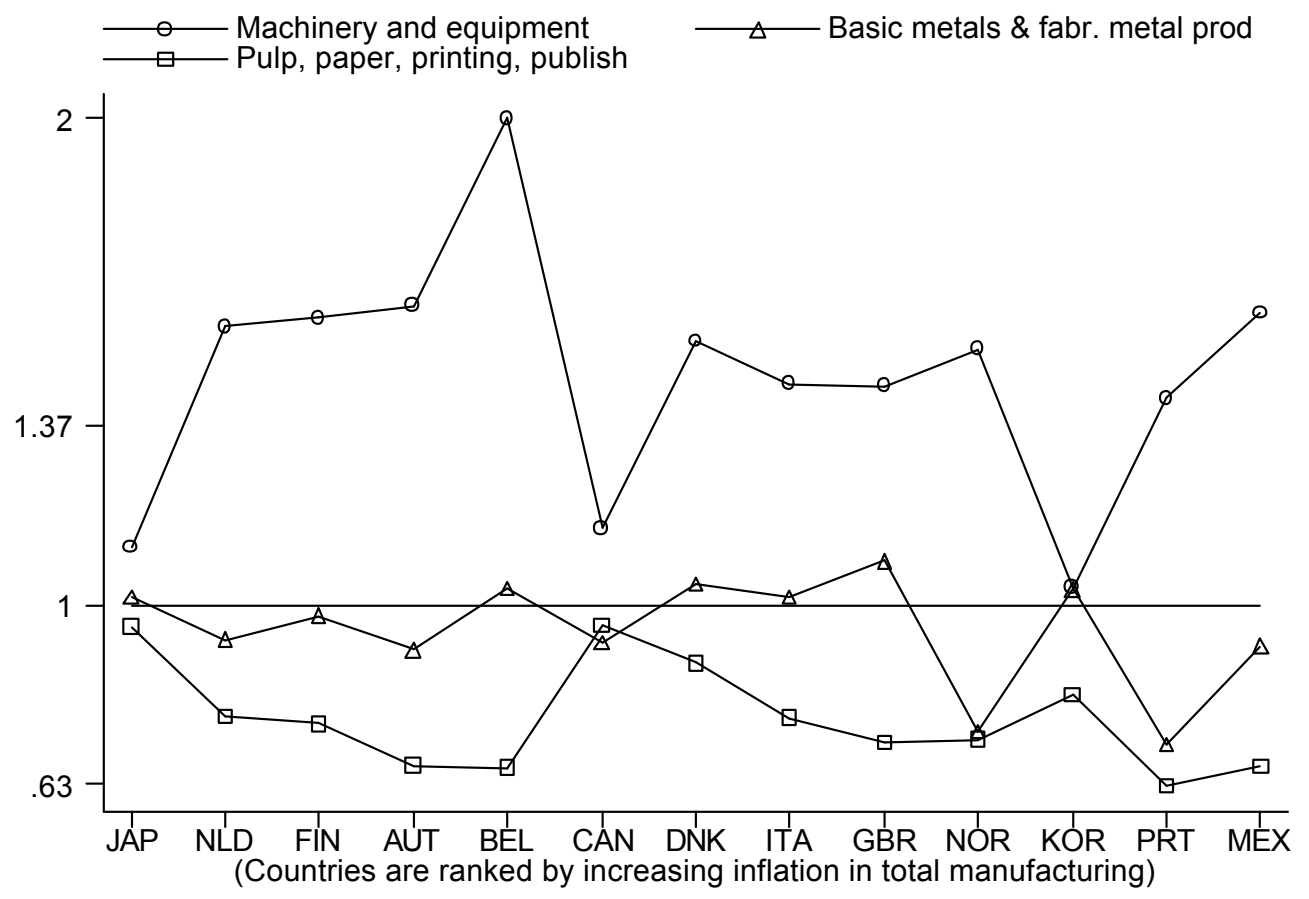


Figure 3: Three convergence tests for the manufacturing sector
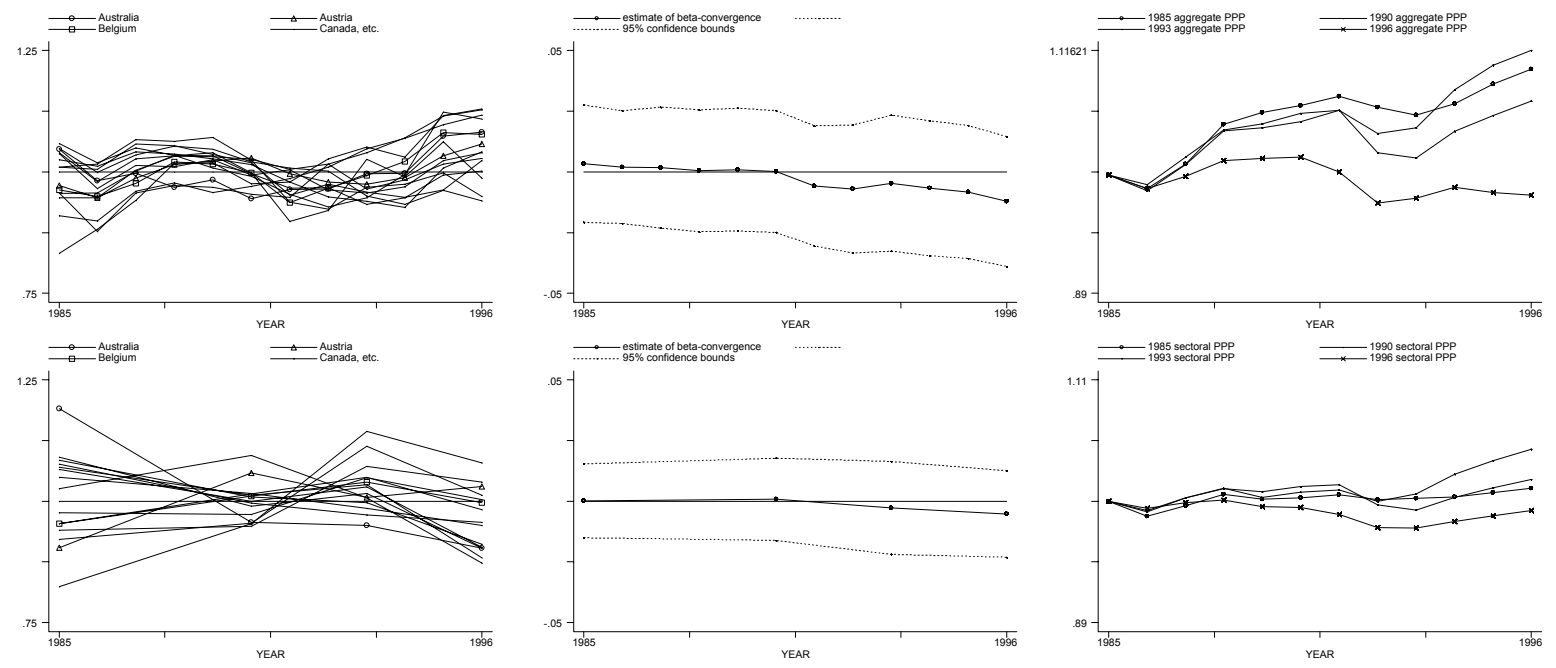
Figure 4: Convergence tests for "Chemical products" (top graphs) and "Financial services and real estate" (bottom graphs)
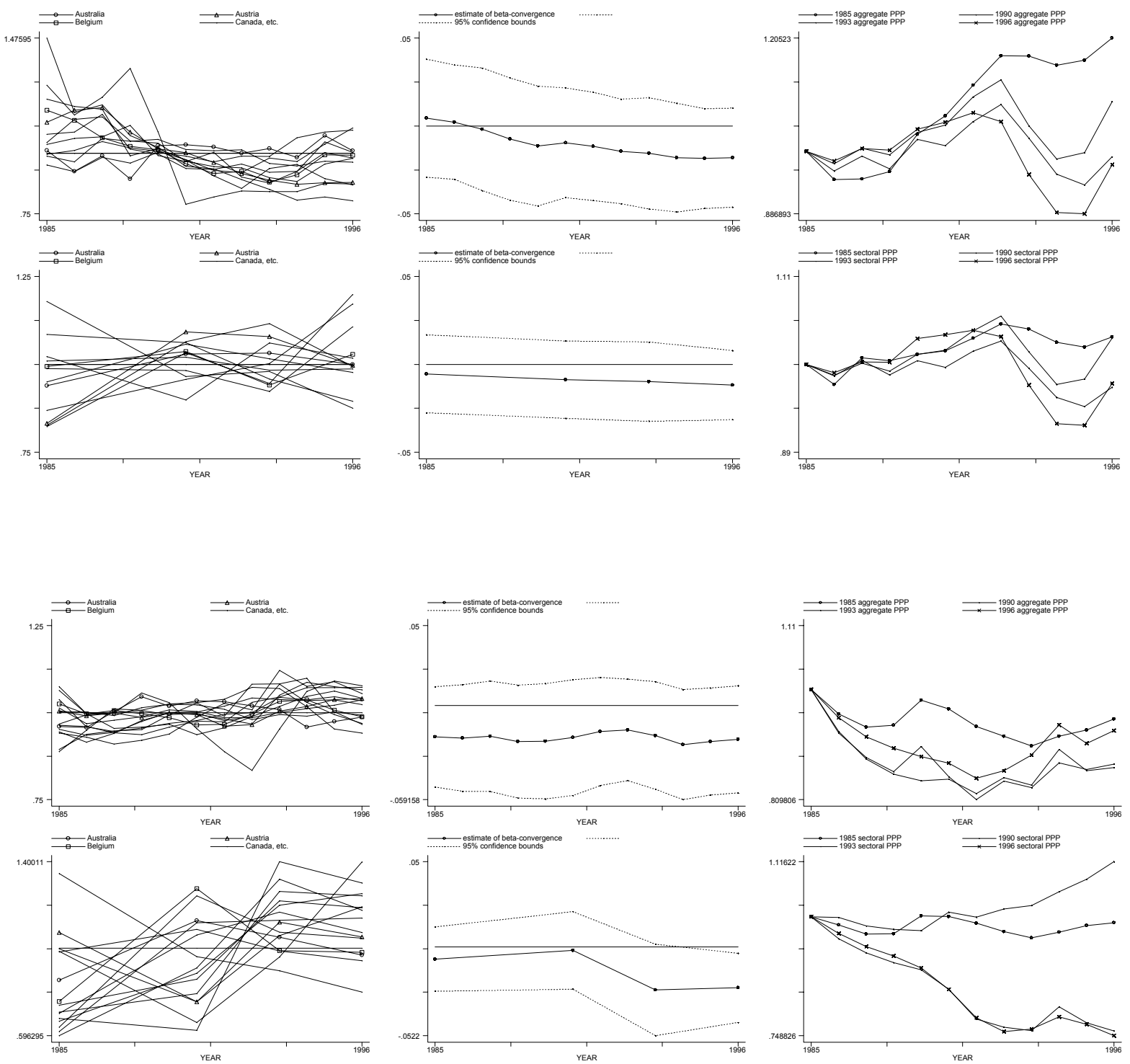
Table 1: Currency conversion factors in 1996

\begin{tabular}{lccccc}
\hline \hline & Exchange & Aggregate & \multicolumn{3}{c}{ Sectoral PPP } \\
\cline { 4 - 6 } & rate & PPP & Total Business & Manufacturing & Textiles \\
\hline Austria & 0.77 & 0.99 & 1.02 & 1.10 & 1.81 \\
Belgium & 0.77 & 0.91 & 0.98 & 1.12 & 1.88 \\
Finland & 0.77 & 0.99 & 1.07 & 1.36 & 1.22 \\
France & 0.78 & 1.00 & 1.06 & 1.19 & 1.71 \\
Germany & 0.77 & 1.04 & 1.05 & 1.12 & 1.91 \\
Greece & 0.71 & 0.63 & 0.80 & 1.03 & 0.96 \\
Italy & 0.80 & 0.82 & 0.93 & 1.09 & 1.44 \\
Netherlands & 0.77 & 0.93 & 0.95 & 1.06 & 1.54 \\
Portugal & 0.77 & 0.61 & 0.76 & 0.99 & 1.66 \\
Spain & 0.76 & 0.74 & 0.81 & 0.96 & 1.29 \\
\hline Australia & 1.28 & 1.30 & 1.36 & 1.62 & 1.86 \\
Canada & 1.36 & 1.19 & 1.23 & 1.44 & 1.48 \\
Denmark & 5.80 & 8.33 & 8.78 & 10.1 & 22.4 \\
United Kingdom & 0.64 & 0.64 & 0.68 & 0.81 & 1.13 \\
Japan & 108.7 & 166.0 & 188.4 & 204.3 & 253.4 \\
Norway & 6.45 & 9.11 & 9.69 & 11.21 & 9.06 \\
Sweden & 6.71 & 9.68 & 10.12 & 11.32 & 11.00 \\
\hline United States & 1.00 & 1.00 & 1.00 & 1.00 & 1.00 \\
\hline \hline
\end{tabular}

For all countries currently in the euro zone, PPPs and exchange rate have been expressed in euros. 
Table 2: Correlation between both measures of relative price changes (1985-96)

\begin{tabular}{|c|c|c|c|c|c|c|}
\hline \multirow[t]{2}{*}{ Industry } & \multirow{2}{*}{$\begin{array}{l}\text { ISIC } \\
\text { Rev. } 3\end{array}$} & \multirow{2}{*}{$\begin{array}{c}\text { \# of } \\
\text { countries }\end{array}$} & \multicolumn{2}{|c|}{ Sectoral PPP } & \multicolumn{2}{|c|}{ Aggregate PPP } \\
\hline & & & $=\operatorname{sign}$ & corr. & $=\operatorname{sign}$ & corr. \\
\hline Agriculture, etc & $01-05$ & 16 & 13 & 0.80 & 12 & 0.78 \\
\hline Agriculture, hunting, forestry & $01-02$ & 8 & 7 & 0.87 & 6 & 0.77 \\
\hline Fishing & 05 & 8 & 7 & 0.80 & 4 & 0.62 \\
\hline Mining and Quarrying & $10-14$ & 14 & 8 & 0.53 & 10 & 0.46 \\
\hline M \& Q of energy products & $10-12$ & 6 & 4 & 0.30 & 6 & 0.50 \\
\hline M \& Q except energy & $13-14$ & 6 & 2 & 0.18 & 2 & 0.11 \\
\hline Manufacturing & $15-37$ & 16 & 12 & 0.78 & 10 & 0.86 \\
\hline Food products and beverages & 15 & 5 & 4 & 0.83 & 3 & 0.61 \\
\hline Tobacco products & 16 & 5 & 4 & -0.74 & 3 & -0.57 \\
\hline Textiles & 17 & 7 & 4 & 0.12 & 3 & 0.59 \\
\hline Wearing apparel & 18 & 6 & 5 & 0.12 & 3 & -0.17 \\
\hline Leather and footwear & 19 & 11 & 4 & 0.41 & 4 & 0.62 \\
\hline Wood and cork & 20 & 12 & 10 & 0.71 & 8 & 0.65 \\
\hline Pulp and paper & 21 & 7 & 5 & 0.07 & 5 & 0.45 \\
\hline Printing and publishing & 22 & 9 & 5 & 0.27 & 4 & 0.17 \\
\hline Coke, petroleum products & 23 & 11 & 7 & 0.32 & 6 & 0.09 \\
\hline Chemicals & 24 & 11 & 8 & 0.79 & 6 & 0.89 \\
\hline Rubber and plastic products & 25 & 10 & 8 & 0.80 & 6 & 0.64 \\
\hline Other non-metallic minerals & 26 & 14 & 6 & 0.66 & 6 & 0.71 \\
\hline Basic and fabricated metals & $27-28$ & 13 & 7 & 0.65 & 8 & 0.82 \\
\hline Machinery and equipment & $29-33$ & 12 & 2 & 0.38 & 5 & 0.74 \\
\hline Transport equipment & $34-35$ & 12 & 8 & 0.69 & 8 & 0.78 \\
\hline Manufacturing nec \& recycling & $36-37$ & 12 & 6 & 0.26 & 7 & 0.82 \\
\hline Electricity, gas and water supply & $40-41$ & 16 & 13 & 0.61 & 11 & 0.79 \\
\hline Construction & 45 & 16 & 7 & 0.70 & 11 & 0.84 \\
\hline Total services & $50-99$ & 14 & 10 & 0.90 & 12 & 0.99 \\
\hline Wholesale and retail; $\mathrm{R} \& \mathrm{H}^{1}$ & $50-55$ & 15 & 7 & 0.70 & 9 & 0.89 \\
\hline Transport and communication & $60-64$ & 15 & 9 & 0.58 & 11 & 0.86 \\
\hline Financial and business services & $65-74$ & 15 & 5 & 0.35 & 12 & 0.94 \\
\hline CSP $_{\text {services }}{ }^{1}$ & $75-99$ & 15 & 14 & 0.91 & 13 & 0.93 \\
\hline
\end{tabular}

${ }^{1} \mathrm{H} \&$ R: hotels and restaurants; CSP: Community, social, and personnel 
Table 3: Correlation between both measures of relative price changes (1993-96)

\begin{tabular}{|c|c|c|c|c|c|c|}
\hline \multirow[t]{2}{*}{ Industry } & \multirow{2}{*}{$\begin{array}{l}\text { ISIC } \\
\text { Rev. } 3\end{array}$} & \multirow{2}{*}{$\begin{array}{c}\text { \# of } \\
\text { countries }\end{array}$} & \multicolumn{2}{|c|}{ Sectoral PPP } & \multicolumn{2}{|c|}{ Aggregate PPP } \\
\hline & & & $=\operatorname{sign}$ & corr. & $=\operatorname{sign}$ & corr. \\
\hline Agriculture, etc & $01-05$ & 16 & 10 & 0.35 & 12 & 0.33 \\
\hline Agriculture, hunting, forestry & 01-02 & 12 & 7 & 0.44 & 8 & 0.35 \\
\hline Fishing & 05 & 12 & 4 & 0.07 & 8 & -0.05 \\
\hline Mining and Quarrying & $10-14$ & 14 & 12 & 0.13 & 10 & -0.02 \\
\hline M \& Q of energy products & $10-12$ & 8 & 6 & 0.17 & 5 & 0.14 \\
\hline M \& Q except energy & $13-14$ & 8 & 6 & 0.34 & 5 & 0.07 \\
\hline Manufacturing & $15-37$ & 16 & 6 & 0.76 & 7 & 0.64 \\
\hline Food products and beverages & 15 & 7 & 3 & 0.74 & 7 & 0.39 \\
\hline Tobacco products & 16 & 7 & 5 & -0.22 & 3 & -0.18 \\
\hline Textiles & 17 & 9 & 8 & 0.62 & 4 & 0.69 \\
\hline Wearing apparel & 18 & 9 & 6 & 0.62 & 6 & 0.35 \\
\hline Leather and footwear & 19 & 13 & 4 & 0.09 & 9 & 0.23 \\
\hline Wood and cork & 20 & 14 & 4 & 0.34 & 8 & 0.16 \\
\hline Pulp and paper & 21 & 12 & 4 & -0.40 & 7 & 0.12 \\
\hline Printing and publishing & 22 & 13 & 9 & 0.27 & 11 & 0.48 \\
\hline Coke, petroleum products & 23 & 12 & 2 & 0.14 & 6 & 0.01 \\
\hline Chemicals & 24 & 14 & 10 & 0.20 & 12 & 0.63 \\
\hline Rubber and plastic products & 25 & 13 & 4 & 0.37 & 6 & 0.44 \\
\hline Other non-metallic minerals & 26 & 16 & 7 & -0.01 & 12 & 0.35 \\
\hline Basic and fabricated metals & $27-28$ & 15 & 6 & 0.22 & 10 & 0.71 \\
\hline Machinery and equipment & $29-33$ & 14 & 0 & 0.07 & 5 & 0.55 \\
\hline Transport equipment & $34-35$ & 14 & 11 & -0.21 & 11 & -0.18 \\
\hline Manufacturing nec \& recycling & $36-37$ & 15 & 9 & 0.09 & 11 & 0.42 \\
\hline Electricity, gas and water supply & $40-41$ & 16 & 10 & 0.13 & 7 & 0.22 \\
\hline Construction & 45 & 16 & 11 & 0.43 & 12 & 0.30 \\
\hline Total services & $50-99$ & 16 & 11 & 0.65 & 12 & 0.68 \\
\hline Wholesale and retail; $\mathrm{R} \& \mathrm{H}^{1}$ & $50-55$ & 16 & 14 & 0.24 & 9 & 0.52 \\
\hline Transport and communication & $60-64$ & 16 & 12 & 0.62 & 10 & 0.36 \\
\hline Financial and business services & $65-74$ & 16 & 11 & 0.01 & 13 & 0.64 \\
\hline CSP $_{\text {services }}{ }^{1}$ & $75-99$ & 16 & 9 & 0.67 & 13 & 0.77 \\
\hline
\end{tabular}

${ }^{1} \mathrm{H} \&$ R: hotels and restaurants; CSP: Community, social, and personnel 
Table 4: Correlation between both measures of relative price changes

\begin{tabular}{|c|c|c|c|c|c|c|}
\hline & \multicolumn{2}{|c|}{$\begin{array}{l}\text { All sectors } \\
\text { in Table } 2\end{array}$} & \multicolumn{2}{|c|}{$\begin{array}{c}\text { Industrial sectors }^{1} \\
\text { in Table } 2\end{array}$} & \multicolumn{2}{|c|}{ All industrial sectors ${ }^{1}$} \\
\hline & number & corr. & number & corr. & number & corr. \\
\hline Australia & 15 & -0.35 & 10 & -0.05 & 13 & -0.38 \\
\hline Austria & 29 & 0.25 & 24 & 0.25 & 37 & 0.28 \\
\hline Belgium & 23 & 0.09 & 18 & 0.20 & 25 & 0.07 \\
\hline Canada & 31 & 0.12 & 26 & 0.15 & 38 & 0.00 \\
\hline Denmark & 31 & 0.09 & 26 & 0.09 & 39 & 0.05 \\
\hline Finland & 31 & 0.13 & 26 & 0.19 & 39 & 0.28 \\
\hline France & 15 & 0.04 & 10 & 0.46 & 15 & 0.09 \\
\hline Germany & 14 & 0.06 & 10 & 0.04 & 15 & 0.01 \\
\hline Great Britain & 27 & 0.22 & 22 & 0.24 & 34 & 0.22 \\
\hline Italy & 25 & 0.36 & 20 & 0.46 & 27 & 0.08 \\
\hline Japan & 27 & 0.38 & 22 & 0.39 & 33 & 0.22 \\
\hline Netherlands & 20 & 0.23 & 18 & 0.25 & 27 & 0.12 \\
\hline Norway & 25 & -0.05 & 20 & -0.07 & 27 & -0.24 \\
\hline Portugal & 20 & 0.02 & 15 & -0.05 & 22 & 0.07 \\
\hline Spain & 10 & 0.61 & 5 & 0.74 & 6 & 0.61 \\
\hline Sweden & 8 & 0.20 & 5 & 0.58 & 6 & 0.91 \\
\hline Average & & 0.15 & & 0.20 & & 0.26 \\
\hline
\end{tabular}

${ }^{1}$ Subsectors of Agriculture, Mining, and Manufacturing; EGW and Construction. 
Table 5: Explaining the correlation between sectoral PPP changes and relative sectoral deflation

\begin{tabular}{lcccc}
\hline & Trade & Mapping & Price change & All 3 \\
\hline Average trade share in VA & -0.633 & & & -1.923 \\
& $(.61)$ & & & $(.49)$ \\
Number of products & & 0.007 & & 0.014 \\
& & $(.01)$ & & $(.01)$ \\
Standard deviation across products & & 1.087 & & 0.800 \\
& & $(.54)$ & & $(.43)$ \\
Single product & -0.138 & & -0.089 \\
& & $(.68)$ & & $(.48)$ \\
Absolute sectoral deflation & & & 1.129 & 0.478 \\
& & & $(1.43)$ & $(1.17)$ \\
Stand. dev. of rel. sectoral deflation & & & 1.604 & 2.705 \\
& 31 & 31 & 31 & $(1.06)$ \\
\hline Observations & 0.04 & 0.16 & 0.32 & 0.63 \\
$\mathrm{R}^{2}$
\end{tabular}

The dependent variable is the ratio of the sectoral to the aggregate correlation coefficient in the fifth and seventh columns of Table 2 
Table 6: Convergence statistics

\begin{tabular}{|c|c|c|c|c|}
\hline Industry & $\begin{array}{l}\text { ISIC } \\
\text { Rev. } 3\end{array}$ & $\begin{array}{c}\text { \# of } \\
\text { countries }\end{array}$ & $\begin{array}{c}\beta \text {-convergence } \\
\text { (OLS coefficient) }\end{array}$ & $\begin{array}{l}\sigma \text {-convergence } \\
\text { (ratio of S.D.) }\end{array}$ \\
\hline Agriculture, etc & $01-05$ & 17 & -0.003 & 0.99 \\
\hline Mining and Quarrying & $10-14$ & 15 & $-0.008^{* *}$ & 0.40 \\
\hline Manufacturing & $15-37$ & 17 & $-0.003^{*}$ & 0.96 \\
\hline Food and tobacco products & $15-16$ & 15 & $-0.007^{* * *}$ & 1.16 \\
\hline Textiles, wearing apparel, leather & $17-19$ & 15 & 0.001 & 0.90 \\
\hline Wood and cork & 20 & 13 & $-0.015^{* * *}$ & 1.13 \\
\hline Pulp, paper, printing, publishing & $21-22$ & 13 & $-0.014^{* * *}$ & 1.11 \\
\hline Chemical and plastic products & $23-25$ & 15 & -0.001 & 0.95 \\
\hline Other non-metallic minerals & 26 & 15 & -0.003 & 0.81 \\
\hline All metals and machinery & $27-35$ & 13 & $-0.004^{*}$ & 0.79 \\
\hline Basic and fabricated metals & $27-28$ & 14 & $-0.005^{* * *}$ & 1.04 \\
\hline Machinery and equipment & $29-33$ & 13 & $-0.013^{* * *}$ & 0.52 \\
\hline Transport equipment & $34-35$ & 13 & -0.006 & 1.09 \\
\hline Manufacturing nec \& recycling & $36-37$ & 13 & -0.002 & 0.78 \\
\hline Electricity, gas and water supply & $40-41$ & 17 & $-0.016^{* * *}$ & 0.80 \\
\hline Construction & 45 & 17 & -0.002 & 1.04 \\
\hline Total services & $50-99$ & 15 & $-0.002^{* * *}$ & 0.95 \\
\hline Wholesale and retail; $\mathrm{R} \& \mathrm{H}$ & $50-55$ & 16 & -0.001 & 0.74 \\
\hline Wholesale and retail trade & $50-52$ & 14 & -0.000 & 0.76 \\
\hline Restaurants and hotels & 5500 & 13 & $-0.005^{* * *}$ & 0.75 \\
\hline Transport and communication & $60-64$ & 16 & $-0.005^{* * *}$ & 1.10 \\
\hline Financial and business services & $65-74$ & 16 & $-0.004^{*}$ & 0.92 \\
\hline CSP services & $75-99$ & 16 & $-0.003^{* *}$ & 0.96 \\
\hline
\end{tabular}

*** Significant at the $5 \%$ level, ${ }^{* *} 10 \%,{ }^{*} 15 \%$. 